REGARDS

SUR LEECONOMIE ALLEMANDE

BULLETIN ECONOMIQUE DU CRAC

\section{Regards sur l'économie allemande}

Bulletin économique du CIRAC

$75 \mid 2006$

Varia

\title{
Entre détermination et attentisme
}

\section{René Lasserre}

\section{OpenEdition}

Journals

Édition électronique

URL : http://journals.openedition.org/rea/524

DOI : 10.4000/rea.524

ISBN : 978-2-8218-0846-1

ISSN : 1965-0787

Éditeur

CIRAC

Édition imprimée

Date de publication : 1 mars 2006

Pagination : 1-2

ISSN : 1156-8992

Référence électronique

René Lasserre, « Entre détermination et attentisme », Regards sur l'économie allemande [En ligne], 75 | mars 2006, mis en ligne le 24 avril 2008, consulté le 22 septembre 2020. URL : http://

journals.openedition.org/rea/524; DOI : https://doi.org/10.4000/rea.524 


\section{Entre détermination et attentisme}

Par delà quelques aléas saisonniers, l'amélioration de la situation économique se confirme et les signes d'une reprise soutenue se multiplient. Dans un contexte international qui reste porteur, la compétitivité externe de l'économie allemande est à son meilleur niveau et devrait permettre à nouveau en 2006, et pour la troisième année consécutive, d'engranger un excédent commercial record. Plus encourageant encore est le fait que la vigueur des performances externes est désormais relayée par une reprise effective de l'investissement dans la plupart des secteurs de l'économie domestique. La demande des ménages ellemême, longtemps anémique, redémarre.

Toutefois, si le climat économique général s'améliore, la confiance des acteurs économiques et des ménages n'est pas complètement sereine, tant l'incertitude reste forte sur l'issue des échéances majeures qui attendent le pays. Le gouvernement d'Angela Merkel a certes pris un bon départ et réussi à asseoir sa crédibilité, la cohésion de l'équipe ministérielle et le bon climat dans lequel travaillent les deux grands partis offrent autant d'éléments rassurants, salués par un large soutien et une réelle popularité dans l'opinion. Pourtant, au fil des jours, cet " état de grâce " qui se prolonge sans accrocs commence à éveiller la perplexité car il semble progressivement se nourrir d'une sorte d'attentisme programmé.

Il apparaît en effet de plus en plus que l'échéance majeure de la politique gouvernementale est fixée au $1^{\text {er }}$ janvier 2007 avec l'entrée en vigueur d'une TVA majorée de 3 points et que l'impact de cette mesure sur l'économie et les finances publiques décidera du succès ou de l'échec de la politique gouvernementale. On commence ainsi à percevoir et à mesurer l'ambivalence d'un programme gouvernemental qui relève davantage du pari que d'une vision construite, qui échelonne les épreuves dans le temps plus qu'il ne présente un schéma de réforme cohérent et qui finalement repousse les choix décisifs à une deuxième phase où les marges de manœuvre risquent d'être devenues incertaines.

L'inconvénient majeur de la démarche est qu'elle entretient l'incertitude et nourrit l'attentisme des acteurs plutôt que de les confronter à des enjeux clairement identifiés : la consolidation budgétaire par le biais d'une hausse importante de l'impôt sur la consommation a semblé politiquement moins douloureuse qu'un programme d'économies budgétaires et plus facilement finançable avec une croissance consolidée. Mais elle présente aussi le risque majeur d'étouffer la croissance attendue et de nourrir l'expectative des ménages et des investisseurs, d'accroître la 
nervosité des partenaires sociaux dans la négociation salariale. Bref de gager l'embellie économique tant escomptée. Quant à la ponction opérée sur le revenu disponible, elle risque ensuite de miner les marges de manœuvre pour la réforme ultérieure incontournable du financement des régimes sociaux.

Certes, le gouvernement Merkel ne cède pas pour autant à l'immobilisme : le programme de relance de l'activité présenté avant Noël est pertinent et judicieux, le budget fédéral et les perspectives budgétaires présentés par Peer Steinbrück le 22 février sont en cohérence avec les choix économiques annoncés et sont crédibles sur le moyen terme. Par ailleurs, les discussions sur la réforme du fédéralisme, qui constitue également une base importante pour l'assainissement financier et une action plus efficace des collectivités publiques, avancent et sont en passe d'aboutir prochainement.

Autant de signes qui montrent que le gouvernement d'Angela Merkel inscrit son action dans la durée, mais qu'en même temps il ne devrait pas attendre 2007 pour commencer à clarifier ses projets de réforme.

René Lasserre

(15-03-06) 